\title{
A DESIGUALDADE NO ACESSO À JUSTIÇA NA BAIXADA FLUMINENSE: ESTUDO DE CASO SOBRE A FUNÇÃO SOCIAL DA COMISSÃO DE MEDIAÇÃO NA UNIVERSIDADE IGUAÇU \\ INEQUALITY IN ACCESS TO JUSTICE IN BAIXADA FLUMINENSE : CASE STUDY ON THE SOCIAL ROLE OF MEDIATION COMMITTEE ON UNIVERSIDADE IGUAÇU
}

\author{
${ }^{1}$ Carmen Caroline Ferreira Do Carmo Nader \\ ${ }^{2}$ Luciane Mara Correa Gomes
}

\begin{abstract}
RESUMO
Este artigo procura analisar o acesso à justiça na Baixada Fluminense com enfoque na Comissão de Mediação da Universidade Iguaçu, objeto da pesquisa empírica realizada, e seu papel social modificador de desigualdades. Nota-se um movimento mundial de acessibilidade judicial, de modo a privilegiar métodos alternativos de resolução de conflitos, com enfoque na mediação, que tornou-se a promessa de um judiciário mais célere, consciente e igualitário. Por meio da pesquisa bibliográfica, busca-se conceituar o acesso à justiça analisando métodos alternativos de resolução de conflitos com ênfase na mediação, apresentando os resultados práticos daquelas realizadas pela Comissão nos anos de 2014/2015.
\end{abstract}

Palavras-chave: Acesso à justiça, Mediação, Desigualdade social

\begin{abstract}
This article analyzes the access to justice in Baixada Fluminense focused on the University Iguaçu Mediation Commission, the empirical research object, and its social role modifier inequalities. Note a worldwide movement of judicial accessibility, in order to favor alternative methods of conflict resolution, focusing on mediation, which has become the promise of a faster, conscious and equal justice. Through literature search, we seek to conceptualize access to justice analyzing alternative methods of conflict resolution with emphasis on mediation, presenting the practical results of those carried out by Commission in the 2014/2015 .
\end{abstract}

Keywords: Access to justice, Mediation, Social inequality

\footnotetext{
${ }^{1}$ Mestranda do Programa de Pós-Graduação em Direito da Universidade Católica de Petrópolis, UCP - RJ, (Brasil). E-mail: carmencaroline@gmail.com

${ }^{2}$ Doutoranda em Sociologia pelo Instituto Universitário de Pesquisas do Rio de Janeiro, IUPERJ - RJ, (Brasil).

E-mail: lucianemara@uol.com.br
} 


\section{INTRODUÇÃO}

O presente artigo está destinado a observar o acesso à justiça na Baixada Fluminense, tendo como referência a Comissão de Mediação da Universidade Iguaçu, vinculada ao Núcleo de Prática Jurídica da universidade, que foi instaurado no início de 2014, visando resolver questões que seriam levadas diretamente ao judiciário, de forma extrajudicial e informal, posto que a mediação é método alternativo de resolução de conflitos, que busca tratar a celeuma como um todo, e não apenas as questões jurídicas apresentadas.

Estando a comissão inserida no Município de Nova Iguaçu, na Baixada Fluminense, marginalizada e, em sua maioria, carente economicamente, com baixo índice de escolaridade e alta criminalidade, busca-se observar como a mediação pode ser medida de facilitação do acesso à justiça e resolução de demandas e diminuição das desigualdades sociais, bem como os aspectos sociais que levam ao sucesso ou insucesso da implementação de tal medida, e como poderá afetar o número de demandas propostas no judiciário, em especial aquelas provenientes da justiça gratuita, público alvo da comissão.

A mediação, enxergada como meio de acesso à Justiça, é o caminho que traz a resposta para ambas as partes interessadas, uma prestação célere e num tempo razoável, de maneira satisfatória. O Tribunal de Justiça do Estado do Rio de Janeiro deu forma às preleções da Resolução n. 125, de 29 de novembro de 2010, do Conselho Nacional de Justiça, por meio da criação do Núcleo Permanente de Mediação de Conflitos, instituindo o projeto que visa restabelecer relações sociais de natureza cível que foram submetidas a uma demanda judicial e que não foram julgados após alguns anos em tramitação, sem ter o resultado pretendido e perpetuando a desigualdade. Estrutura-se o trabalho a partir de conceitos doutrinários para mediação, como também a ponderação dos doutrinadores acerca da sua aplicabilidade e o confronto com a crise existente no campo judiciário para a lentidão na entrega da prestação jurisdicional.

O marco teórico é estabelecido na virtude da Justiça, encontrada em Tomas de Aquino para construir a igualdade entre as partes litigantes e assim fixar o princípio da paridade de armas, necessário ao processo e que, com a mediação, é restabelecido no decorrer das sessões dialogadas. 
Cabe ponderar que o tratamento é igualitário às partes que buscam a composição por este método, através do reconhecimento pelo Estado de sua eficiência, diante das possibilidades de dar uma resposta aos indivíduos envolvidos, como também conferir à Universidade uma dinâmica diferenciada no ensino das técnicas de interpretação do Direito e operacionalidade destes conhecimentos adquiridos.

É por meio da Comissão de Mediação que realiza a implementação das técnicas de solução de conflitos, que a Universidade Iguaçu tem prestado à comunidade do entorno o estreitamento dos laços entre partes que perderam a capacidade de dialogar, a oportunidade de restabelecer relações jurídicas afetadas pelos efeitos nocivos decorrentes da perda da confiança, bem como a diminuição das desigualdades latentes na Baixada Fluminense com a facilitação e efetivação do acesso à justiça.

Cumpre esclarecer que o Núcleo de Prática Jurídica ao qual a Comissão de Mediação é vinculada atende mensalmente pessoas que são consideradas pobres na acepção da Lei, e não teriam outro meio de acesso à justiça ou à resolução de seus conflitos não fosse a Defensoria Pública, que por sua vez não tem condições de abarcar como deveria a enorme quantidade de demandas nas quais é solicitada. Sendo assim, o Núcleo funciona como um verdadeiro "braço" da mesma, de modo a auxiliar recebendo demandas que são “escoadas” da Defensoria Pública do Estado na Comarca de Nova Iguaçu.

A instalação da Comissão de Mediação da Universidade Iguaçu dá acesso ao acadêmico do curso de Direito às técnicas de mediação, instituto inserido no ordenamento jurídico pela Lei Federal 13.105, de 16 de março de 2015, em vigor desde o dia 18 de março de 2016, como também concretiza a função social da universidade ao estabelecer uma política pública de pacificação de controvérsias.

A metodologia de trabalho se dá pela análise qualitativa dos dados obtidos no período de fevereiro a maio e agosto a novembro de 2014 e janeiro a julho de 2015, e, muito embora as estatísticas decorrentes dos atendimentos feitos no âmbito da Comissão de Mediação da Universidade Iguaçu ainda não sejam capazes de refletir no número de ações distribuídas na Comarca de Nova Iguaçu do Tribunal de Justiça do Estado do Rio de Janeiro, bem como promover efetiva inclusão social das camadas hipossuficientes por meio do acesso à justiça, este trabalho desenvolvido tem reflexos positivos no que se refere ao resultado prático pretendido nestas demandas. 
Este ponto é primordial para compreender que a universidade tem atingid o seu papel social de entregar à sociedade, bacharéis em Direito capazes de dialogar em conflitos sociais que têm dificuldade de comunicação, seja por sua natureza, seja por sua complexidade.

\section{HOMEM E AS MUDANÇAS SOCIAIS}

O homem mediano tem a estrita necessidade de estar inserido numa sociedade constituída por paradigmas, como se visualiza no ambiente acadêmico, no núcleo religioso, ou até mesmo no local de trabalho. Esta posição encontra respaldo em Bastos (2012, p. 174) que ao analisar os fatos sociais, entende que os fatos sociais devem ser tratados como coisas, sob a ótica conceitual de Emile Durkheim, o que significa que os fatos sociais são externos ao próprio homem e, para reconhecê-los devem ser observados e experimentados avançando do exterior acessível até o invisível profundo.

Enxergado na sociedade com culturas massificadas, como mais um, este indivíduo é lançado num ambiente onde a pluralidade de informações, contratos e relações jurídicas são despejados sob a mesma forma, podendo ser sentido até na forma com que o Estado vai regrar a vida em sociedade, uma vez que esta experiência é mundial, nos dizeres de Calamandrei (2004, p. 72).

Traduzindo na expressiva forma de desenvolvimento do direito (BASTOS, 2012,p. 175) este movimento, vai conduzir o indivíduo a uma posição beligerante para que o mesmo se sinta inserido na proteção de sua cidadania, alcançando seu direito de acesso à Justiça. Na visão deste indivíduo, conseguir sua cidadania é no sentido de preterir a negociação, a composição pacífica das controvérsias à alcançar uma lide com a obtenção de uma prestaçã o jurisdicional a fim de valorar a Justiça da decisão, como se fosse um troféu.

Neste espaço, faz-se necessário abrir uma lacuna para se entender a virtude da Justiça, ou, melhor dizendo, a Justiça como virtude a ser satisfeita ou ser apaziguada a composi ção do conflito por outros meios senão a propositura de uma lide. Aqui se reporta à Platão, quando expõe que justo é dar a cada um o que lhe é apropriado (2014, p. 40).

Como encontrar o equilíbrio para este homem moderno submetido a uma carga de litigiosidade excessiva pelas mazelas sociais sem que se sinta inferior pela opção aos meios alternativos de solução de conflitos, posto que um dos propósitos básicos da lei é 
resolver o conflito, e a solução do conflito geralmente envolve a limitação da autonomia de alguém (SIMON, 2001, p. 45).

Retomando as considerações de Platão sobre o justo, não é o que cada um diz o que é, mas o que está em voga é a virtude da Justiça sob a utilidade dada a esta função sem prejuízo de qualquer outro ser humano (PLATAO, p. 45). No entanto, existem valores mais elevados do que aqueles consignados na norma, valores que estão para além da interpretação estrita do instrumento legal, a intenção do legislador, este julgamento por equidade, já descrito por Comparato (2006, p. 488) está em voga desde os ideais de Roma, a serviço de um só propósito: conciliar o seu próprio interesse com o interesse universal.

A inclusão, conceito que tem sido bastante debatido nos meios acadêmicos, tem seaprofundado no sentido de se pensar num tipo de conceito de antiexclusão para que antigos paradigmas possam ser substituídos por conceitos de inclusão. Os processos sociais de integração e exclusão são ambos muito importantes, uma vez que a ação de integração social pode ser uma parte decisiva na medida em que cobre situações nas quais haja resistência contra a adoção de medidas inclusivas dentro de organizações e de espaços excludentes da sociedade (SASSAKI, 2001).

Em uma sociedade de baixa mobilidade social, onde as desigualdades se mostra m latentes e expõe as fraquezas e mazelas dos indivíduos, cabe ponderar nas palavras de Araújo, et el (2009, p. 81):

\begin{abstract}
As relações entre os indivíduos e os grupos são marcadas pela desigualdade social na história. A estrutura de classes consolida-se no capitalismo com a propriedade privada, a divisão social do trabalho e o Estado Moderno. As formas de estratificação social fundamentam-se em critérios econômicos, políticos e sociais, aplicados de modo individualizado. As classes sociais são agrupamentos de indivíduos inseridos no processo de produção e partilham interesses comuns e uma identidade. O lugar social de cada um é definido pela posição econômica que o indivíduo ocupa na estrutura social e essa posição influencia estilos de vida, escolhas pessoais, gostos e ocupações. A desigualdade social sinaliza a baixa mobilidade social e expõe a concentração de riquezas nas sociedades capitalistas.
\end{abstract}

Cappelletti (1988, p. 15) assegura que a efetividade perfeita se completa com a igualdade de armas. Mas como pensar este conceito diante de um país-continental como o Brasil, principalmente quando a direção desejada pelo indivíduo é que seja assegurada uma vida humana adequada (PASSOS , 2005, p. 13). 
Desta forma, iniciativas como a Comissão de Mediação da Universidade Iguaçu se mostram importantes para compreender e quiçá modificar esses processos sociais. Neste aspecto, cabe transcrever o posicionamento de Pinho (2012, p. 390) no que se refere à universalização do acesso à Justiça pelas pessoas hipossuficientes, pois não basta garantir o direito à distribuição de uma demanda no Poder Judiciário, salutar se faz obter o auxílio de um advogado para promover a defesa das partes ou até mesmo decifrar as leis cada vez mais complexas. Desta forma, está inserto no conceito de cidadania, tido como direitos fundamentais, políticos, sociais e econômicos e difusos, ante a uma valoração da liberdade, num aspecto temporal de sua evolução, obter o acesso à Justiça como meio de equilíbrio de valores.

É preciso, tomar como ponto de partida a busca por uma identidade brasileira do acesso à Justiça para entendê-lo como se faz efetivo, exigível e tangível, diante da realidade nacional estar envolta num arcabouço burocrático e carecedor de infraestrutura do Poder Judiciário, uma vez que não basta o discurso de fazer um acesso organizado, pois este acesso precisa ser pleno.

O que se observa é que com o abarrotamento do judiciário, a resolução das celeumas precisa ser cada vez mais rápida, o que as torna massificadas, insatisfatórias e pouco efetivas, servindo como um verdadeiro "cumprir tabela" do judiciário brasileiro.

\section{O DIREITO DE ACESSO À JUSTIÇA}

O direito de acesso à justiça no Brasil surgiu na Constituição de 1946, sofrendo mudanças ao longo do tempo. Encontra hoje respaldo no inciso XXXV da CRFB/ 88 e não pode ser visto como mero direito de acesso ao judiciário, mas sim como algo maior, compreendendo o acesso a uma ordem jurídica justa e extensiva ao maior número de pessoas.

As chamadas “Ondas renovatórias de Capelletti e Garth", consideradas um marco em relação aos métodos alternativos de resolução de conflitos, propõe assistência judiciária aos menos favorecidos, representação dos interesses difusos (interesses fragmentados ou coletivos, como o meio ambiente saudável ou a proteção ao consumidor) combinando ações coletivas e advogados públicos, entre outros, além de um novo enfoque de acesso à justiça, com a inserção de métodos alternativos de resolução de conflitos, o que não significa retirar o caráter fundamental da justiça tradicional. 
Esses movimentos geraram reformas estruturais no Judiciário, visando tornar a justiça mais acessível e adequada à sociedade contemporânea, sendo importante a conscientização de que os Tribunais não são o único meio de resolução de conflitos.

\subsection{OS MECANISMOS EXTRAJUDICIAIS DE RESOLUÇÃO DE CONFLITOS}

O conflito é comum ao ser humano, e três são as formas de se obter a solução do conflito de interesses: Autotutela (ou autodefesa, que é a solução violenta do conflito pela força, permitida pelo Ordenamento somente em situações excepcionais, não podendo ir além do indispensável), heterocomposição (solução atribuída exclusivamente a terceiros) e autocomposição (solução pacífica e por meio dos próprios interessados, muitas vezes mediante intervenção de um terceiro).

A expressão "meios alternativos de resolução de conflitos" é relativamente recente, segundo El-Hakin (1997, Apud, AMARAL, 2009, p.61), sendo originada das Alternative Dispute Resolution (ADR), que se desenvolveu nos EUA da década de 1980, como alternativa a justiça tradicional centrada na figura do juiz. Tais métodos existiriam desde as primeiras sociedades humanas, já que alguns autores destacam que arbitragem teria surgido na Babilônia 3 milênios AC como combate à autotutela, utilizada pelo homem desde épocas remotas. Era usada por líderes religiosos e políticos, possibilitando o diálogo e promovendo a aptidão das partes em encontrar soluções consensuais para a resolução de conflitos. O paradigma de "ganhar-perder" é substituído por "ganhar-ganhar", já que o método tradicional privilegia o litígio, enquanto os meios alternativos privilegia m o diálogo.

$\mathrm{O}$ Projeto Florentino de Acesso à Justiça, estudo pioneiro realizado em 1978 patrocinado pela Fundação Ford, teve como objeto de estudo os meios alternativos de resolução de conflitos, no qual se concluiu pela necessidade de utilização de formas conciliatórias e alternativas, além de tribunais especiais compostos por juízes leigos. Segundo Capelletti, "há situações em que a justiça conciliatória é capaz de produzir resultados que, longe de serem de "segunda classe", são melhores, até qualitativamente, do que os resultados do processo contencioso (CAPPELLETTI, 1994, p. 126), especialmente nos conflitos de vizinhança e família, por envolver uma relação complexa e permanente. 
Além de mais democráticos, são métodos que buscam ser mais rápidos, informais, algumas vezes com menor custo e mais eficientes em muitos casos.

\subsubsection{A Conciliação}

Expressão oriunda do latim conciliatione, ato ou efeito de conciliar, ajuste, acordo ou harmonização dos litigantes. Sua origem é remota e controversa. Segundo Medina (2004, Apud Amaral, 2009, p. 71) tem-se notícia da sua existência entre os hebreus, gregos antigos e na Lei das XII Tábuas, sem ser possível precisar, contudo, se os mecanismos utilizados à época eram ao menos similares com os utilizados atualmente. Adotada no Brasil na Carta de 1824, que seguiu o modelo da Revolução Francesa, instituindo a exigência de tentativa de conciliação prévia.

Segundo Tartuce (2015, p. 48):

Por tal técnica de autocomposião, um profissional imparcial intervém para, mediante atividades de escuta e investigação, auxiliar os contendores a celebrar um acordo, se necessário expondo vantagens e desvantagens em suas posições e propondo saídas alternativas para a controvérsia, sem, todavia, forçar a realização de um pacto.

Muito disseminada no Direito Brasileiro, em especial nos Juizados Especiais Cíveis e Criminais com base na Lei $n^{\circ} .9 .099$ de 26 de setembro de 1995, tem por objetivo a realização de acordo entre os litigantes, mas não se propõe e resolver de forma integral o conflito mediante o restabelecimento do diálogo. Em razão do sucesso obtido em sua utilização nos Juizados Especiais citados, foi ampliada para os Juizados Especiais Federais, com base na Lei $n^{\circ} .10 .259$ de 2001.

Nota-se que uma das principais diferenças entre a conciliação e a mediação está no tipo de relação para o qual são indicadas, sendo a primeira para relações sem vínculos prévios e sem expectativa de mantê-los no futuro, como algumas relações de consumo, enquanto a mediação direciona-se especialmente para questões de relação continuada, como as familiares, por exemplo. Esta posição assumida é pautada nas lições de Vasconcelos (2015, p.60):

É apropriada para lidar com relações eventuais de consumo e outras relações casuaispessoas sem vínculos anteriores, em que não prevalece o interesse comum de manter um relacionamento, mas, fundamentalmente, o objetivo de equacionar interesses materiais ou questões jurídicas. 
Fato é que a conciliação vista sob o prisma do judiciário abarrotado e incapaz de lidar com a quantidade de demandas apresentadas, tornou -se procedimento mecânico, repetitivo e ineficaz, muitas vezes sendo considerada "etapa morta" do procedimento, fazendo com que o mesmo arraste-se por mais tempo, aumentando as expectativas e, consequentemente, frustrações das partes quando a sentença não traz a satisfação desejada.

\subsubsection{A ARBITRAGEM}

No Brasil, foi tratada na Constituição de 1824 e adotada pelos Códigos de Processo Civil de 1939 e 1973. Definida como (CARMONA, 1993, p. 19):

\footnotetext{
(...) uma técnica para solução de controvérsias através da intervenção de uma ou mais pessoas que recebem seus poderes de uma convenção privada, decidindo com base nessa convenção, sem intervenção do Estado, sendo a decisão destinada a assumir a eficácia de sentença judicial.
}

Poderá ser de direito ou equidade, dependendo da vontade das partes, que podem submeter a solução de seus conflitos ao juízo arbitral, a partir da convenção de arbitragem, seja por cláusula compromissória, seja por compromisso arbitral. Sendo assim, convenção de arbitragem é gênero, no qual cláusula compromissória e compromisso arbitral são espécies. A primeira é genérica e abrange um número indeterminado de lides, enquanto a segunda é específica, visando a solução de lides existentes e perfeitamente delimitadas.

Pode ocorrer quando as partes realizam um contrato e convencionam que qualquer questão dele resultante será resolvida mediante arbitragem, o que é feito mediante cláusula compromissória, anterior ao surgimento do conflito. Também ocorre quando já existe o conflito e as partes decidem submetê-lo à decisão de um árbitro, sendo firmado o compromisso arbitral.

O árbitro pode ser alguém de confiança das partes, podendo ser um ou mais, desde que em número ímpar e não necessita de formação superior, desde que tenha capacidade civil e técnica para resolver o conflito. Muito utilizado em situações que exijam 
conhecimentos especializados, o que foge à alçada da maioria dos magistrados, pode ser uma boa solução para a morosidade dos processos, uma vez que em conflitos que exijam especialização (causas que necessitem de perícia técnica, como demarcação de terras, por exemplo), poderia o árbitro ser um especialista de confiança das partes.

Sendo assim, não seria necessário ingressar com uma ação judicial, solicitar perícia ao juiz, que nomeia o perito, que realiza a mesma e devolve aos autos para a decisão final. Esse longo procedimento, que pode durar muito tempo, seria simplificado e reduzido, poupando esforço e tempo das partes, já que o árbitro seria perito e julgador na questão. Ainda pouco utilizada em demandas de massa, é mais presente em questões comerciais cujas partes tenham interesse em resolver o problema mantendo o sigilo e discrição.

\subsubsection{MEDIAÇÃO: MECANISMO DE DIMINUIÇÃO DAS DESIGUALDADES SOCIAIS.}

A palavra mediação provém do latim mediatio, que significa intervenção, intercessão, intermediação. Assim, mediação é um procedimento voluntário de resolução de conflitos, no qual um terceiro imparcial dá assistência às pessoas em litígio, com a finalidade de que possam manter uma comunicação produtiva à procura de um acordo possível para elas.

Como método de resolução de conflitos, atua como um dos tripés do Projeto de Florença, que, entre outros objetivos, buscou observar os espaços em que a prestação fornecida pelo Poder Judiciário seria incapaz de otimizar os resultados pretendidos nas demandas.

De acordo com o estudo, averiguou -se que a mediação é instrumento capaz de fornecer a solução rápida das divergências e o eficiente controle jurisdicional do seu funcionamento e dos seus resultados, ou seja, a busca de uma justiça melhor (GRECO, 2015 , p. 23).

Neste aspecto, se faz oportuno salientar que o estudo da aplicabilidade da mediação está para além do poder de império que a decisão judicial é revestida, pois, na prática, a mediação tem como função controlar os conflitos sociais, sem imposição, por consenso (VOESE, 2010, p. 26). 
Como é parte dos objetivos fundamentais da República Federativa do Brasil a construção de uma sociedade justa com a redução das desigualdades sociais, a mediação ainda deve ser construída como instrumento de negociação atribuidor de maior liberdade às partes. Desta forma, é necessário que se tome a conceituação de Justiça, sob a ótica de Tomas de Aquino, como significado de igualdade. Fazendo a conexão de igualdade com justiça, na esfera do conflito social que é posto em juízo, tem-se a igualdade material - quando se aborda a necessidade do indivíduo - bem como a formal - estabelecendo instrumentos normativos que contribuam para atingir às postulações dos indivíduos que não são dotados de meios para alcançarem a prestação jurisdicional pelos aspectos burocráticos, jurídicos e econômicos.

Em se considerando o estudo da Justiça, em Tomás de Aquino, detecta-se que a desigualdade das pessoas pode lhes conceder uma igualdade proporcional (NUNES, 2013, p.527).

Finalmente, a igualdade segundo a posição e condição particular das pessoas concentra a distribuição de encargos e ônus segundo a melhor ou pior condição de determinados grupos de pessoas, considerando a posição e classe em que se situam (aristocratas, oligarcas, plebeus e servos). Nesse particular, o critério de tratamento igual e desigual concerne não à riqueza de cada grupo de pessoas (que concentra a igualdade segundo a capacidade contributiva), mas a uma determinada raça, determinado credo, um determinado idioma e uma determinada estratificação social que seja considerada como padrão de superioridade natural entre certos e determinados grupos de pessoas. Nesse critério de igualdade, entende-se regular a existência da escravidão e da submissão de determinados grupos a outros simplesmente em razão de certas condições pessoais originárias sobretudo do nascimento. Entende-se que, em função disso, as pessoas são naturalmente desiguais, merecendo, pois, naturalmente, tratamento distinto por uma questão de igualdade proporcional.

Neste parâmetro, ao "estar no meio", como real sentido do significado da mediação, é adotar um modo de construção e de gestão da vida social da qual quem opta por mediar está disposto a aceitar restabelecer a comunicação (MORAIS, SPRINGLER, 2012, p. 131).

Segundo Pinho (2012, p. 883), entende-se a mediação “como o processo por meio do qual os litigantes buscam o auxílio de um terceiro imparcial que irá contribuir na busca pela solução do conflito”. É importante destacar que esse terceiro não tem missão de decidir, 
nem a ele foi dada autorização para tanto, ele apenas auxilia as partes na obtenção da solução consensual. A mediação por este prisma deve ser compreendida como o viés de comunicação e vem sendo referendada na Lei n. 13.105 de 16 de março de 2015, com a equiparação da condição do mediador judicial a auxiliar da justiça, regrada nos artigos 165 a 175, a promoção de solução consensual do litígio uma marca neste Código (MARINONI, 2015, p.97).

Como espécie de autocomposição, a mediação deve ser embasada na identificação e eliminação das causas que geraram o conflito, surgindo daí a necessidade de qualificação do profissional atuante na mediação.

Considerada um método dialogal, especialmente indicado para conflitos interpessoais e relações continuadas, apresenta a vantagem de resolver a questão de forma integral, e não apenas a lide processual, sendo um método eficaz, contribuindo para um efetivo acesso à justiça (AMARAL, 2009, p. 89) Além disso, pode atuar previamente, na medida em que educa para a solução autônoma dos próprios conflitos, promovendo mudanças nos relacionamentos sociais e por consequência, a pacificação social.

Em definição de Guillaume - Hofnung (2007, p. 71 Apud AMARAL, 2009, p.91):

\begin{abstract}
(...) a mediação se define principalmente como um processo de comunicação ética baseado na responsabilidade e autonomia dos participantes, no qual um terceiro imparcial, independente, neutro e sem poder decisório ou consultivo com uma única autoridade que lhe foi reconhecida pelos mediados - propicia mediante entrevistas confidenciais o estabelecimento ou restabelecimento de relação social, a prevenção ou a solução da causa.
\end{abstract}

Propícia quando utilizada em situações em que se busque manter o relacionamento entre as partes, onde o litígio contenha contextos mais profundos (emocionais e psicológico, por exemplo), bem como a ruptura do diálogo. Sendo assim, é mais apropriada para resolver conflitos advindos de relações de múltiplos vínculos, como as familiares, de amizade, de vizinhança, uma vez que através desse processo é possível preservar as reçlações.

A Lei n. 13.105, de 16 de março de 2015, em seus artigos 165 a 175, dispõe sobre a mediação entre particulares como meio de solução de controvérsias e também sobre a autocomposição de conflitos no âmbito da administração pública, equiparando, desta forma, a condição do mediador judicial a auxiliar da justiça, busca a promoção de solução consensual do litígio. 


\section{A COMISSÃO DE MEDIAÇÃO DA UNIG}

A UNIG - UNIVERSIDADE IGUAÇU foi fundada em 1970, sendo o curso de Direito implementado em 1974. Além do Curso de Direito, a Universidade possui diversos outros cursos vinculados à cinco Faculdades: Ciências Biológicas e da Saúde, Ciências Exatas e Tecnológicas, Educação e Letras, além de Ciências Jurídicas e Sociais Aplicadas. Fora o Campus I, onde funciona a sede em Nova Iguaçu, possui ainda outros quatro Campi ativos distribuídos na Baixada Fluminense, sendo um dos mais importantes o Campus III, onde está localizado o Centro de Formação Profissional, que abrange o Núcleo de Prática Jurídica (NPJUR), o Escritório de Prática Jurídica (ESAJUR), além de possuir pólos conveniados do PROCON e SEBRAE.

O ESAJUR, Escritório de Assistência Jurídica, vinculado ao Núcleo de Prática Jurídica da Universidade Iguaçu (UNIG) implementou, em fevereiro de 2014, a Comissão de Mediação, cujo objetivo é utilizar a mediação de conflitos como solução de litígio restabelecendo o diálogo entre as partes, além de proporcionar ao graduando em direito contato com a prática da mediação por intermédio de profissionais capacitados e comprometidos.

Inédita entre as universidades da Baixada Fluminense, a iniciativa do ESAJUR traduz a função social da Universidade, que estabelece papel fundamental para o fomento à cidadania por intermédio do acesso aos meios de resolução de conflitos extrajudiciais, além de auxiliar o judiciário, na medida em que diminui gradativamente a quantidade de demandas propostas.

O ESAJUR busca estabelecer o diálogo entre sociedade hipossuficiente da Baixada Fluminense e a Universidade, por meio da Assistência Jurídica Universitária. Tendo em vista que a Defensoria Pública do Estado, órgão constitucionalmente incumbido de atender aos vulneráveis economicamente, não tem condições materiai s de suportar tamanha demanda, o Escritório de Prática Jurídica acabou tornando-se um verdadeiro bálsamo para aqueles que não têm condições de suportar as inúmeras filas e o atendimento massificado pela enorme quantidades de demandas que necessitam do auxílio deste Órgão. Sendo assim, as partes que têm dificuldade de acesso físico, ou mesmo não têm condições de chegar cedo e suportar filas enormes para os atendimentos na Defensoria, são 
encaminhadas, pelos próprios estagiários do Órgão para o ESAJUR, e lá, após a triagem inicial e informações adequadas, algumas são direcionadas para a Comissão de Mediação.

Além de terem contato com a prática jurídica de forma holística e multidisciplinar, os alunos integrantes do Núcleo são instigados a terem uma visão crítica e humana do direito, condizente com as necessidades da população local, em especial a atendida pelo Núcleo, tendo em vista que o mesmo se presta a assistir os hipossuficientes.

A Comissão de Mediação da Unig foi criada em fevereiro de 2014 com o objetivo de estimular o diálogo entre as partes assistidas pelo Escritório de Assistência Jurídica, ESAJUR, de modo a solucionar ou prevenir situações de litígio ou impasse. A ideia é a da criação de oportunidade para que as partes discutam, questionem e contestem os seus conflitos abertamente, com fins de solução consensual entre eles. $\mathrm{O}$ atendimento ocorre durante todos os dias da semana, em sala específica e preparada para tal, em horário comercial.

Com base no relatório dos atendimentos realizados entre fevereiro a maio e agosto a novembro de 2014, além de janeiro a julho de 2015, pudemos observar que houve um número crescente de homologações de acordo:

Em fevereiro de 2014, das 30 mediações realizadas, 11 foram arquivadas por falta de interesse e 7 foram solucionadas por acordo. Em março, por conta de recessos e feriados, os números caíram para 18 mediações, das quais 05 foram arquivadas por falta de interesse, e 02 foram homologadas com acordo. Em abril, das 28 mediações realizadas, apenas 04 foram arquivadas por falta de interesse, e 04 foram homologadas. Já em maio, das 30 mediações realizadas, 11 foram arquivadas por falta de interesse e 07 homologadas.

Já nos meses de Agosto a novembro de 2014, após as férias acadêmicas, fora $\mathrm{m}$

realizadas 35 mediações, das quais 17 foram positivas, e apenas 3 arquivadas por falta de interesse. As demais foram mediações negativas (10 ao todo, onde houve demanda judicial) e

05 decorrentes de ausência da parte convocada.

No período de janeiro a julho de 2015, das 65 (sessenta e cinco) mediações designadas, 58 (cinquenta e oito) eram da área de família e 7 (sete) da área cível, sendo realizadas 32 (trinta e duas) na área de família e 3 (três) na área cível, o que 
representa um êxito em quase metade das demandas encaminhadas, totalizando 35 (trinta e cinco) mediações.

Observa-se que em pouco mais de um ano de funcionamento, 72 (setenta e dois) acordos foram homologados, o que significam 72 (setenta e dois) processos a menos para o Poder Judiciário, e, ao menos, 144 partes dialogando para chegar a um consenso. Ainda que esse número, num primeiro momento, não signifique grande impacto na imensa quantidade de demandas propostas no judiciário, é inegável que já demonstram impacto nos resultados práticos pretendidos nessas demandas, que muitas vezes tem desdobramentos além do conflito suscitado (questões familiares e relacionadas aos Juizados Especiai s Criminais geralmente são associadas, e vice-versa), atendendo ainda como política pública, os conflitos de interesses devem não só objetivar uma boa qualidade dos serviços, como também difundir a cultura da pacificação social.

Observa-se também que dentre as demandas propostas, a maioria se refere a questões de Direito de Família, em especial Divórcio e Alimentos, o que denota o caráter humanístico e transformador da mediação para o núcleo familiar, base de formação do indivíduo. Sendo assim, o alcance dos benefícios das mediações realizadas vão muito além das demandas apresentadas pelas partes, pois sendo a família o primeiro microssistema em que o indivíduo está inserido, e tendo a mesma harmonia e diálogo, certamente vai reverberar como benefício para a sociedade da qual ele faz parte.

\section{CONSIDERAÇÕES FINAIS}

O direito de acesso à Justiça, considerado direito social básico, passou a ser concebido como direito material, e não uma garantia meramente formal, onde se busca criar condições para o exercício efetivo de postular em juízo, e garantir a proteção dos direitos individuais e coletivos.

As deficiências do sistema jurídico vigente mais apontadas como a morosidade, custos elevados, número insuficiente de juízes, sobrecarga de processos, entre outras situações, assim como uma cultura de maior participação dos cidadãos para a solução dos litígios por meio do diálogo e do consenso, têm propiciado o desenvolvimento dos meios 
alternativos de resolução de conflitos, que não visam a eliminação da justiça estatal, mas sim uma forma rápida, econômica e que atenda às mudanças da sociedade contemporânea. Se adotadas as vias da mediação, o Judiciário poderá se concentrar em causas mais complexas, como as que versam sobre os direitos indisponíveis, e aquelas que discutam relações de forte desequilíbrio econômico entre as partes, tornando mais viável o acesso à Justiça, propiciando a cidadania efetiva.

A mediação é instituto democrático, pois propicia a inclusão social ao orientar e conscientizar os indivíduos sobre seus direitos e faculta às partes a resolução de seus conflitos por elas mesmas, por meio do diálogo. Em razão da expectativa de seus baixos custos, informalidade, ênfase dada ao diálogo, ajuda não somente na resolução da controvérsia, mas na resolução do conflito em si, promovendo a pacificação social, cidadania e autonomia, podendo ser considerada um modo efetivo e emancipador do acesso à Justiça e de equalizador social.

Muito embora se trate de pesquisa em andamento, observa -se por meio das estatísticas obtidas no relatório da Comissão, que em pouco mais de um ano de funcionamento da Comissão de Mediação da UNIG, 72 (setenta e dois) acordos foram homologados, o que significam 72 (setenta e dois) processos a menos no Judiciário, e 144 (cento e quarenta e quatro) partes dialogando para chegar a um consenso, bem como ganhando autonomia para a resolução de seus próprios conflitos. Observa-se que a grande maioria das questões envolve conflitos familiares, ou seja, de natureza continuada. Tais conflitos englobam muito mais do que questões jurídicas, mas sim questões psicológicas, sociais e familiares, que por sua vez, envolvem partes que inicialmente não se apresentam no conflito judicial. Por exemplo, um caso de divórcio decidido nos tribunais, muitas vezes não contempla as questões de guarda por total falta de diálogo entre as partes. Ainda que judicialmente um divórcio só tenha como litigantes o casal, fato é que seus efeitos se estendem por toda a família. É nesse ponto que a mediação se mostra eficaz e educativa, uma vez que resolve a questão como um todo, e não apenas o conflito judicial, ensinando as partes a buscar autonomia para a resolução de seus próprios conflitos.

Outro ponto importante é o fato de que nas populações de baixa renda, a práxis demonstra que questões familiares geralmente desencadeiam questões criminais e vice-versa. Ou seja: o conflito ganha vulto tal, que torna as questões muito mais graves e, muitas vezes, irreversíveis. 
Enquanto populações de alta renda e padrão social possuem inúmeros meios de resolução de conflitos (fácil acesso à justiça, acesso a advogados, mediação e arbitragem, por exemplo), e são educadas serem autônomas, o mesmo não ocorre com as camadas de baixa renda, que vêem o Estado como único salvador, encarnando o judiciário de justiceiro e único defensor de seus direitos.

A mudança de paradigmas proporcionada pela mediação, espera-se, gerará a longo prazo profundas mudanças sociais e, quiçá, diminuição das desigualdades, uma vez que propiciando o acesso efetivo à justiça de forma satisfatória e eficaz, está contribuindo para a autonomia cidadã daqueles que são excluídos do sistema vigente, seja por serem "invisíveis" pra sociedade, seja pela inacessibilidade decorrente dessas desigualdades. 


\section{REFERÊNCIAS:}

AMARAL, Márcia Terezinha Gomes. O Direito de Acesso à Justiça e a Mediação. Rio de Janeiro: Lumem Juris, 2009.

ARAUJO, Silvia Maria de; BRIDI, Maria Aparecida; MOTIM, Benilde Lenzi. Sociologia: um olhar crítico. São Paulo: Contexto. 2009.

BARRETTO, Vicente de Paulo (Org). Dicionário de Filosofia do Direito. Rio de Janeiro: Renovar. 2006.

CALAMANDREI, Piero et alli. A crise da justiça. Tradução de: Hiltomar Martins Oliveira, Belo Horizonte: Editora Líder, 2004.

CAPPELlETTI, Mauro. GARTH, Bryant. Acesso à Justiça. Tradução de Ellen Gracie Northfleet. Porto Alegre: Fabris, 1988.

CARMONA, Carlos Alberto. A arbitragem no processo civil brasileiro. São Paulo: Malheiros, 1993.

COMPARATO. Fabio Konder. Ética: direito, moral e religião no mundo moderno. São Paulo: Companhia das Letras, 2006.

EL - HAKIN, Jaques. Les modes alternatifs de réglement des conflits dans le droit des contrats. In: Revue international de droit compare, pp. 312-407, avril - juin 1997.

FILPO, Klever Paulo Leal; BAPTISTA, Bárbara Gomes Lupetti; NUNES, Thais Borzino Cordeiro. Os caminhos da Mediação no Brasil e na Argentina. Artigo Científico. Congresso Internacional Sociologia Direito em Movimento. Porto Alegre, 2015.

FISHER, Roger; URY, William; PATTON, Bruce. Como chegar ao SIM: negociação de acordos sem concessões. Tradução: Vera Ribeiro e Ana Luiza Borges. Rio de Janeiro: Imago, 1994.

GRECO, Leonardo. Instituições de processo civil. Volume I. $5^{\text {a }}$ Ed. Rio de Janeiro: Forense, 2015.

GUILlaUME-HOFNUNG, Michéle. La Méditatión. 4. Ed., Paris: Presses Universitaires de France - PUF, Que sais-je?, 2007.

GOMES, Luciane Mara Correa. NADER, Carmen Caroline Ferreira do Carmo. Mediação como política pública: a sociedade reclama um Judiciário mais sensível aos conflitos sociais. IV Jornada de Ciências Sociais UFJF - "As Ciências Sociais: Caminhos e interseções". 10 a 13 de novembro de 2015, UFJF, Juiz de Fora-MG, p. 4.

MARINONI, Luiz Guilherme. Novo Curso de Processo Civil. Volume 1.2015 
MORAIS. José Luis Bolzan de. SPENGLER, Fabiana Marion. Mediação e arbitragem: alternativa à jurisdição! $3^{\mathrm{a}}$. Ed. rev. e atual. com o Projeto de Lei do novo CPC brasileiro. (PL 166/2010), Resolução 125/2010 do CNJ. Porto Alegre: Livraria do Advogado. 2012.

NUNES, Claudio Pedrosa. A conceituação de justiça em Tomás de Aquino: um estudo dogmático e axiológico. Curitiba: Juruá, 2013.

PINHO, Humberto Dalla Bernardino de. O novo CPC e a Mediação: Reflexões e Ponderações. Disponível em http://www.humbertodalla.pro.br/artigos.htm. Acesso em 13 de fevereiro de 2016.

A mediação no Direito Brasileiro. Evolução, atualidades e possibilidades no Projeto do Novo Código de Processo Civil. Disponível em http://www.humbertodalla.pro.br/artigos.htm. Acesso em 09 de fevereiro de 2016.

A mediação na atualidade e no futuro do processo civil brasileiro. Disponível em http://www.humbertodalla.pro.br/artigos.htm. Acesso em 12 de fevereiro de 2016.

PLATAO. A república (ou Da Justiça). Tradução, textos complementares e notas Edson Bini. 2a edição, $1^{a}$ reimpressão. São Paulo: EDIPRO, 2014.

SARLET, Ingo Wolfgang. Dignidade da Pessoa Humana e Direitos Fundamentais na Constituição Federal de 1988. $5^{\text {a }}$ Ed, rev. atual. Porto Alegre: Livraria do Advogado, 2007.

SASSAKI, R.K. Pressupostos da Educação Inclusiva. 2001. Disponível em http://www.wvaeditora.com.br. Acesso em 14 de fevereiro de 2016.

SIMON, William H. A prática da justiça: uma teoria da ética dos advogados. Tradução Luís Carlos Borges. São Paulo: Martins Fontes, 2001.

VOESE, Ingo. Mediação dos conflitos como negociação dos sentidos. $7^{\mathrm{a}}$ reimpressão. Curitiba: Juruá, 2010. 